\title{
AOIR
}

Selected Papers of \#AoIR2020:

The 21 st Annual Conference of the Association of Internet Researchers Virtual Event / 27-31 October 2020

\section{IN THE SHADOWS OF THE DIGITAL ECONOMY: THE GHOST WORK OF INFRASTRUCTURAL LABOR}

What does digital piecework have in common with laboring in the warehouse of a large online shopping platform? How is data cleaning related to digitization work and $\mathrm{Al}$ training in prisons? This panel suggests bringing these diverse ways of laboring in the digital economies together by considering these practices as infrastructural labor that takes the shape of shadow work (Illich, 1981) and ghost labor (Gray \& Suri, 2019). In recent years, critical infrastructure studies have turned our attention to the social practices and the work that goes into developing, building, repairing and maintaining infrastructures of communication (Parks and Starosielski, 2015). Susan Leigh Star (1999) has pointed to the importance of making visible the ordinary work that is involved in infrastructure building and maintenance, including the labor of janitors and cleaners (see also Parks \& Starosielski, 2015). Sarah T. Roberts (2019) investigates the casualized labor of content moderators in social media spaces in a global context. This includes studying the work that emerges with and through media infrastructures such as Downey's study of telegraph messenger boys between 1850 and 1950. Like the messenger boys, the cases of digital labor considered in this panel constitute examples of emerging forms of work at the intersection between automation and physical labor, forms of work that combine machine labor with human labor and human labor that makes machine automation possible in the first place. The integration of analyses of labor with questions of infrastructure, hence, points to the socio-technical character of infrastructures and that they always have to rely on human productive activity.

Work and labor in modern, capitalist society imply power, authority and possibility for resistance, and these dimensions are crucial for understanding why and how infrastructures are realized and how they work. Infrastructure labor is ambiguous. It is both visible and invisible depending on the specific tasks and their inherent power relations (Leigh Star \& Strauss, 1999). It includes both manual and cognitive labor. It is geared towards innovation as well as repair, maintenance and servitude.

Suggested Citation (APA): Kaun, A., Velkova, J., Laaksonen, S., Delfanti, A., Logsdon, A., Stiernstedt, F., Lehtiniemi, T., Ruckenstein, M. (2020, October). In the Shadows of the Digital Economy: The Ghost Work of Infrastructural Labor. Panel presented at AolR 2020: The 21 th Annual Conference of the Association of Internet Researchers. Virtual Event: AolR. Retrieved from http://spir.aoir.org. 
The individual contributions discuss diverse forms of infrastructural labor ranging from data practices to make and keep data clean (paper 1), human extended machine labor at warehouses (paper 2), digitization and media work at prisons (paper 3 ) and prisoners training $\mathrm{Al}$ (paper 4). Through bringing this range of practices together, the panel aims to paint the contours of infrastructural labor at the margins of digital economies pointing towards forms of alienation and resistance that have long been part of labor relations, but that are renegotiated in the context of emerging technologies within digital economies that need human labor to be sustained and further innovated.

\section{References}

Gray, M. L., \& Suri, S. (2019). Ghost Work. How to Stop Silicon Valley from Building a New Global

Underclass. Boston, MA: Houghton Mifflin Harcourt.

Leigh Star, S., \& Strauss, A. (1999). Layers of Silence, Arenas of Voice: The Ecology of Visible and Invisible Work. Computer Supported Cooperative Work, 8, 9-30.

Parks, L., \& Starosielski, N. (2015). Introduction. In L. Parks \& N. Starosielski (Eds.),

Signal traffic: Critical studies of media infrastructures (pp. 1-27). Urbana:

University of Illinois Press.

Roberts, S.T. (2019) Behind the Screen: Content Moderation in the Shadows of Social Media.

New Haven: Yale University Press.

Illich, Ivan (1981). Shadow Work. Boston: Marian Boyars. 


\title{
Extended Abstracts
}

\section{CLEANING DATA: THE SOCIO-TECHNICAL CONSTRUCTION OF ORDER IN THE DIGITAL ECONOMY}

\author{
Julia Velkova \\ Linköping University \\ Salla-Maria Laaksonen \\ University of Helsinki
}

Data has become the 'raw' material used to produce value in the digital economy, and turned into an object around which many fields of scientific and economic activity constitute themselves (Ruppert et al., 2017; Kitchin, 2014). Data, however, is never raw, as Lisa Gitelman famously formulated. Instead, it is collected, curated, mined and analyzed, and simultaneously constantly re-imagined through social and cultural practices. In short, data needs human care at various stages of its lifetime. In this paper we explore the cultural practices and social understandings of cleanliness that emerge at distinct infrastructural layers of the digital economy at which data-related practices are performed. Critical data studies have previously acknowledged the centrality of various forms of processing involved in data practices (Beer, 2019; Kitchin, 2014). A much discussed form of data processing and cleaning has been identified at the level of social media content where human labour is central for removing inappropriate content (Gillespie, 2018; Ruckenstein \& Turunen, 2019). At the production level, infrastructure studies have problematised the energy-intense labour of machines in coal-powered data centres, which enable data processing, but with significant consequences for the environment, local communities and urban infrastructure (Hogan, 2018; Velkova, 2016). Hence, symbolic cleanliness and environmental pollution have emerged as categories that define data practices in terms of labour, value and care.

This paper extends these debates by ethnographically engaging with the social and technological practices of 'cleaning' data at two infrastructural layers of its production as a commodity in platform capitalism -in data centres and in data analytic companies. Theoretically, we develop our discussion of cleanliness drawing upon perspectives from STS and anthropology on the cultural work and significance of ordering and classification (Douglas, 1966/2002; Bowker \& Star, 2000). As Douglas (2002) wrote, dirt is a relative category which offends against a desired order. It destabilises that order by introducing internal contradictions to a social system, confronting it with its own anomalies, engendering understandings of danger. Likewise, practices of classification (Bowker \& Star, 2000) represent a mechanism to align different agendas and form relationships between disparate actors. Examining different understandings that cleanliness takes within data analytics companies and data centres offers the possibility to see how the labour of keeping data clean aligns and synchronises different parts of the digital economy. 
Empirically, we draw on ethnographic data and interviews collected in four Finnish social media analytics companies and within two data centres located in Finland. The analytics companies varied in size and stage, but all employed computational text mining methods instead of using mainstream platform metrics. The data centres were operated by a global platform data giant and a collocation service provider. In all sites, data were collected during one-week-long participatory observation periods, during which detailed field notes and visual material was collected, and altogether 23 informants were interviewed across the sites.

Our findings illuminate the centrality of cleanliness in data practices, and the variety of social and economic ends to which cleanliness is mobilised. In the context of social media analytics the idea of cleaning data emerges as strongly connected to enabling economic value creation. Cleaning encompasses either filtering the data (i.e. leaving only relevant and valuable parts) or enriching the data (i.e., using sophisticated methods to extract information, such as recognizing named entities or analysing the sentiment). These practices are hidden from the public sight and from the customers to whom the analysis of data is being sold: they are part of the rehearsed 'magic' of technology (Bowker \& Star, 2000). Both filtering and enriching work to prepare the data for future uses and simultaneously work to generate those desired futures for the data use. Cleanliness is essential; the function of the analysis is to detach the messy original context, put the data in order in a new, cleaner context, and to generate and sell a sense of control. Hence, cleanliness is about reduction and removal of anomalies which are either not regarded profitable, or could disturb a dominant logic towards which analysis and value production from data is being geared (cf Douglas, 2002).

Data is also being maintained clean at the very physical, elemental level, within the industry-scale production infrastructures that provide the computational power for data processing -- data centres. The cleanliness of data in this context takes two dominant orientations. First, it defines the temporal mode of producing value from data, by organising computing equipment that underpins data analytics to uphold a factory ideal of uninterrupted production (cf. Noble, 1986). To achieve this ideal, the natural and human environments from within servers compute data are constantly purified to secure incessant computation; incoming air is filtered from dust, floors and cables are scrubbed and kept sterile, diesel generators are kept meticulously clean. Second, the sterility of the physical environment where data computation takes place has also a discursive function, to frame data within a collective vision of future-oriented data-driven industrial production. In difference from the social media analytics context where data is omnipresent, in the data centre, data is invisible. The physical space of its computation and ordering is similar to that of many other industrial processing factories, such as power plants or chair assembly factories. Yet, the cleanliness of the space produces a sense of modernity for the workers, and of belonging to a digital future that they are invisibly maintaining.

Taken together, the different forms and orientations that cleanliness takes in our empirical contexts point to a logic of infrastructural alignment of data processing practices. In this logic, the human work of cleaning in contexts of data processing organises temporally data practices turning them into a continuous form of production, 
which is then also ordered symbolically and discursively. This form of ordering produces the 'factory sublime' (Nye, 2007) that surrounds data, a sense of awe and astonishment around digital industries under transformation. The seeming purity of computation environments as well as the urge to produce clean data reflect and reinforce the belief in the value of data processing, legitimising it both for the market, for the local communities, and for the workers who labour in these facilities.

\section{References:}

Beer, D. (2019). The data gaze. London: Sage.

Bowker, G., \& Star, S. L. (2000). Sorting things out. MIT press.

Douglas, M. (2002). Purity and Danger. London: Routledge.

Hogan, M. (2018). Big data ecologies. ephemera 18(3), 631-657.

Gillespie, T. (2018). Custodians of the Internet. New Haven: Yale University Press.

Noble, D. (1986). Forces of Production: A Social History of Industrial Automation. New York: Oxford University Press.

Nye, D. (2007). American Technological Sublime. Cambridge, Mass.: MIT Press.

Kitchin, R. (2014). The Data Revolution. London: SAGE.

Ruckenstein, M. \& Turunen, L. (2019). Re-humanizing the platform: Content moderators and the logic of care. New Media \& Society, 1461444819875990.

Ruppert, E., Isin, E., \& Bigo, D. (2017). Data politics. Big Data \& Society, 4(2), 205395171771774.

Velkova, J. (2016). Data that warms: Waste heat, infrastructural convergence and the computation traffic commodity. Big Data \& Society 3(2), 1-10. 


\title{
HUMANLY EXTENDED AUTOMATION, OR THE FUTURE OF WORK SEEN THROUGH AMAZON PATENTS
}

\author{
Alessandro Delfanti \\ University of Toronto
}

In the last few years, the multinational corporation Amazon has contributed to anxieties about automation through a series of innovations that aim at reducing its reliance on living labour. Amazon stores the commodities it sells through its e-commerce websites in hundreds of gigantic warehouses, or fulfillment centers (FCs), located at the periphery of major urban areas across the world. Each employs thousands of workers who manually store or retrieve the commodities customers purchase through the website. Management uses Amazon's massive digital infrastructure to capture worker knowledge about warehouse inventory and thus organize the labour process downstream, as well as to control and discipline workers (Delfanti 2019). Yet while today's FCs require masses of workers performing physical and repetitive tasks, the introduction of new robots which move shelves or pack boxes generated news attention as a harbinger of automation, ultimately pointing to a future "lights out" warehouse populated only by machines.

Exploiting their public nature, I strategically use patents owned by Amazon to take a glimpse at technology that the corporation may one day introduce in its fulfillment processes. The design stage is a major step through which the relationship between machines and humans materializes, and studying it helps unearth the political and contested nature of technology. But a closer look at the thousands of patents owned and submitted by Amazon suggests that humans are not about to disappear from warehouses anytime soon. Indeed, many portray a warehouse floor in which machines increase worker surveillance and work rhythms, for example in the case of a bracelet used to capture data from and provide feedback on workers' movements. Others, such as task allocation algorithms or sensors that analyze available space in shelves, seem to aim at segmenting the labour process and thus increasing the corporation's ability to increase the productivity of its workforce. Visors and wearable technologies that capture data from workers' activities incorporate this knowledge into machinery and use it to rationalize the labour process in an ever more pervasive form of digital Taylorism. For example, data extracted from workers' activity is used to train robots. Patents materialize the company's desire for a technological future in which humans extend machinery and become its living and sensing appendages.

We refer to the new relationship emerging from such technologies as a form of humanly extended automation. The concept derives from a foundational 1960 essay on humancomputer interaction, in which American psychologist and computing pioneer J. C. R. Licklider imagined forms of automation in which human operators serve the technology, which he called "humanly extended machines." The idea of machines extended by humans also flips McLuhan's famous idea of media as extensions of human senses and organs (1964). Instead, Amazon's patents imagine humans as extending machinery's ability to perceive, learn from, and act upon the environment. By adopting Licklider's 
definition, we propose that Amazon's future warehouse automation may further Marx's idea of workers being reduced to the "conscious organs" of machinery in a future automatic factory in which "it is the machine which possesses the skills, it is itself the virtuoso, with a soul of its own" (1973: 693). In an industrial era dominated by the steam engine, as in Marx's time, workers provided physical input, for example feeding raw materials to machinery, digital machinery feeds on workers' mental and sensory operations as much as their muscle. Rather than representing the liberated cognitive power of the multitude, here Marx's general intellect should be seen as "capital's accumulated machinic capacities, excised from social human labour" (Dyer-Witheford et al. 2019).

We identify three key forms in which the continued presence of humans and the increased digitization of their work in the warehouse manifests as humanly extended automation. First, machines surveil workers and control and intensify their labour. This is based on increased machinic control over workers, decomposition and taskification of their activities, and further automation of managerial functions. Second, automation captures and datafies workers' activities and tacit knowledge to recursively improve in a form of Taylorism that optimizes not just human work but machinic processes too. Third, humanly extended automation is based on a division of labour between humans and robots in which workers are increasingly exchangeable with automated technology and intervene mostly to make up for robots' shortcomings.

This paper is based on content analysis from over 200 patents issued to Amazon in the last five years and targeting technology related to inventory management and warehousing. It is built around three bodies of theory. First, Marxist theory including early Italian operaismo authors such as Mario Tronti (1966) and Raniero Panzieri (1961) contextualizes the role of technology in production processes. Second, feminist technology studies authors such as Judy Wajcman (2017) or Atanasoski \& Vora (2019) allow to nuance issues of power distribution and the ways in which worker bodies are invisibilized in patents. Third, social theorists such as John Urry (2016) and Barbara Adam (2000) help me analyze the extent to which patents grant ontological status to futures that are produced and traded, although not materially present.

As they work to sustain and improve the digital infrastructure that makes their labour possible, workers contribute to shaping an increasingly machinic future workplace. Through myriads of sensors and other devices, workers will act and sense on behalf of Amazon's technological infrastructure. Once incorporated into ever-evolving machinery, datafied worker activities and knowledge may provide the foundations for the automation of further processes. Borrowing from a patent, one can safely assume that "it is inevitable [...] that the paths of the robots and humans working in the warehouse will cross." The authors of this patent are concerned because "direct contact between the human workers and the robots [...] can be problematic, and a maintenance issue for the robots" (Stubbs 2018). I am rather concerned with new technology's potential to create maintenance issues for the workers, as they face ever-innovated forms of inequity and are increasingly subordinated to machines, as dreaded by 1960 s operaismo and 2010 s feminist technology studies alike.

\section{References}


Adam, B. (2000). Foreword. In Brown et al. (eds) Contested futures, pp. xii-xiii, Ashgate.

Atanasoski N \& Vora K (2019) Surrogate Humanity. Race, Robots, and the Politics of Technological Futures. Durham: Duke University Press.

Delfanti, A. (2019). Machinic dispossession and augmented despotism: Digital work in an Amazon warehouse. New Media \& Society, online.

Dyer-Witheford, N., Kjøsen, A.M., and Steinhoff, J. (2019) Inhuman Power. Artificial Intelligence and the Future of Capitalism. London: Pluto Press.

Licklider, J.C.R. (1960) Man-Computer Symbiosis. IRE Transactions on Human Factors in Electronics 1, pp. 4-11.

Marx K (1973) Grundrisse. New York: Penguin

McLuhan M (1964) Understanding Media: The Extensions of Man. New York: McGrawHill.

Panzieri R (1961) Sull'uso capitalistico delle macchine nel neocapitalismo. Quaderni rossi 1: 53-72.

Stubbs, A., et al. (2018). System and methods to facilitate human/robot interaction, United States Patent No. US 9,889,563 B1

Urry J (2016) What is the future? London: Polity.

Wajcman, J. (2017) Automation: Is it really different this time? The British Journal of Sociology, 68(1), 119-127. 


\title{
LOGGED IN AND LOCKED UP? DIGITAL LABOR IN PRISONS
}

\author{
Anne Kaun \\ Södertörn University \\ Alexis Logsdon \\ University of Minnesota Libraries \\ Fredrik Stiernstedt \\ Södertörn University
}

\begin{abstract}
Digital workers can be locked out-or choose to log out-from digital platforms. But there's a class of digital workers who cannot log out from their platforms because they're locked up. Incarcerated workers are largely overlooked in research on labor in general and digital labor in particular, but they have long contributed to crucial societal infrastructures, including media and digital infrastructures. From leased workers building the railway in the US to constructing the canal systems in Sweden, prisoners' labor has been widespread as an important part of value production.
\end{abstract}

In the current day, part of the labor conducted by incarcerated individuals is related to the production, repair and maintenance of media devices and media infrastructures constituting what we call prison media work (Kaun \& Stiernstedt, 2020). Additionally, prisoners are increasingly providing labor to state agencies, including libraries and state archives, in order to produce digitized records for preservation, research, and recreation (Logsdon, 2019). In other contexts, prisoners are producing valuable training data for artificial intelligence and machine learning (see fourth presentation in the panel).

Work and productive labor are central aspects of prison life. Prisons have accordingly been called "factories behind bars" (LeBaron, 2008) and Torsten Eriksson, the former director general of the Swedish Prison and Probation Service, in a debate book on penal ideals in Sweden quotes the motto of the architectural committee of the correctional services "we build the factory first and then the prison that belongs to the factory" (Eriksson, 1966; see also Nilsson, 2017). In the postwar period in Sweden, factory work and prisons were imagined as closely integrated and to provide "meaningful" work as an important part of the penal logic. The idea of integrating work into the prison everyday life was translated into modern prison architecture in Sweden around that time and big "factory prisons" such as Hall and Kumla were built. Industrial work in the prison context developed rapidly after the Second World War and was increasingly integrated into rehabilitation programmes for prisoners.

The work conducted by prisoners has historically ranged from assignments for internal purposes such as simple administration, laundry, cleaning and cooking, to work assignments for external companies and public institutions. The work in prisons as well as convict leasing has been addressed, though not extensively, earlier (Davis, 2003; Gilmore, 2007; Mancini, 1996; Nilsson, 2017). What has been underexplored so far is a specific part of prison work that relates to media or what we call prison media work. This 
includes the construction of crucial media-related infrastructures such as laying cables, producing parts of infrastructures such as electronic equipment, envelops and mail bags for the postal system as well as maintenance work on such infrastructures for example repair shops for television and radio sets and the dissembling of obsolete devices (Conrad, 2011). Because the labor conducted by prisoners most often includes manual labor that does not require specific or extensive training to perform, few have considered the relationship between prison labor and media work. However, of the three categories that the Swedish Prison and Probation Services has used to organize prison labor throughout the 20th century - namely, agriculture, forestry and industry - industrial work conducted within prisons has often included media work. Today, this production has its developed own brand, Made In Prison, to market its products. In the US, prisoners are employed to digitize newspapers for state archives, yearbooks, and genealogical records, adding a deeper layer to already obscured labor of digitization of the cultural record.

We conceptualize prison media work in similar terms as Kelly Gates has done for ironically - police media labor that encompasses among other things "the work of wearing cameras is transformed into scalable, infrastructural labor, and where the individual videos and embodied work activities involved in digitally recorded policing become valuable objects of exchange in the police media economy" (Gates, 2015). Gates' conceptualization and investigation of police media labor provides also an important taxonomy that allows to develop a typology of prison media work:

"Like most forms of media work, the media labor that the police perform is simultaneously immaterial and material, cultural and technical, mental and manual. Far from providing individual police workers with an empowering creative outlet for self-expression, it requires a repudiation of creative subjectivity, by and large serving the risk-management needs of police organizations and policing as an institution. It also serves the direct and indirect aims of a variety of interconnected industries - a set of aims and connections that require further research." (Gates, 2015)

We argue that prison media work ranges from material to immaterial work, from technical to cultural and from manual to cognitive work. In the analysis, we show the historical movement from material to immaterial, from technical to cultural and from manual to mental work. Prison media work as empirical phenomenon and theoretical conception extends ongoing debates on work and labor in media studies that have focused on questions of creativity (Hesmondhalgh \& Baker, 2011), exploitation (Qiu, 2016) and hidden precarious labor (Mayer, 2011).

This presentation draws on empirical research conducted in the US and European context concerning digital labor of prisoners. Bringing together research on historical forms of prison media work in the Swedish context with explorations of contemporary digital labor in US-american prisons, this presentation develops insights on digital labor in prisons beyond national jurisdiction and prison regimes. We conceptualize the digital labor conducted as a) industrial-like, repetitive work and b) the work of being tracked generating data as a resource of digital infrastructures. Digital pieceworkers on platforms such as Mechanical Turk and Upwork work isolated and disconnected from 
each other forestalling political organization. Digital labor in prisons takes this alienation and invisibility to its extreme. Consequently, we argue that although the prison context has often been considered as fundamentally outside of mainstream society, the logics of digital labor in prisons are the dark mirror of labor under surveillance capitalism.

\section{References}

Kaun, A. \& Stiernstedt, F. (2020). Prison Media Work: From Manual Labor to the Work of Being Tracked. Media, Culture and Society. OnlineFirst https://journals.sagepub.com/doi/full/10.1177/0163443719899809

Conrad, S. M. (2011). A Restorative Environmental Justice for Prison E-Waste Recycling. Peace Review, 23(3), 348-355. doi: 10.1080/10402659.2011.596071

Davis, A. (2003). Are Prisons Obsolete? New York: Seven Stories Press.

Eriksson, T. (1966). Kriminalvård på anstalt [Corrections in the institution]. In J. Freese (Ed.), Kriminaliteten och samhället [Criminality and society]. Stockholm: Bokförlaget Aldus/ Bonniers.

Gates, K. (2015). The work of wearing cameras: body-worn devices and police media labor. In R. Maxwell (Ed.), Routledge Companion to Labor and Media. London: Routledge.

Gilmore, R. W. (2007). Golden Gulag: Prisons, Surplus, Crisis and Opposition in Globalizing California. Berkley: University of California Press.

Hesmondhalgh, D., \& Baker, S. (2011). Creative Labour: Media work in the three cultural industries. London: Routledge.

LeBaron, G. (2008). Captive labour and the free market: prisoners and production in the USA. Capital \& Class, 32(2), 59-81.

Logsdon, A. (2019). Ethical Digital Libraries and Prison Labor? Digital Library Federation Forum.

Mancini, M. (1996). One Dies, Get Another: Convict Leasing in the American South 1866-1928. Columbia: University of South Carolina Press.

Mayer, V. (2011). Below the line: producers and production studies in the new television economy. Durham: Duke University Press.

Nilsson, R. (2013). From learning to labour to learning to self-control: the paradigmatic change in Swedish prison policy. Journal of Scandinavian Studies in Criminology and Crime Prevention, 14(sup1), 24-45.

Qiu, J. (2016). Goodbye iSlave: A manifesto for digital abolition. Urbana: University of Illinois Press. 


\title{
PRISONERS TRAINING AI
}

\author{
Tuukka Lehtiniemi \\ University of Helsinki \\ Minna Ruckenstein \\ University of Helsinki
}

The history of capitalism can be told as a history of constantly transforming new things into cheap resources. Data has been called "the next big cheap" (Pendergrast, 2019), something separated from its original context, reinvented as a commodity, and absorbed within the capitalist production system. Drawing from critical research on political economy, data has been examined as a new form of capital, and dataveillance as the method and online platforms as the apparatus of data production. However, data are rarely usable without human input, as recent examinations of task-based "ghost work" (Gray \& Suri, 2019) remind us. Hidden human labour is involved in producing, labeling and editing data - necessary tasks for transforming data into a commodity. Platforms like Amazon Mechanical Turk successfully turn human piecework into an ondemand, machine-accessible resource for data production. Data becomes the next big cheap only by means of re-organising a more traditional big cheap, human labour.

We examine an unconventional case of task-based human labour in data: prisoners labeling Finnish-language data for an Al firm. With a focus on data labour, we argue against connotations of machinic intelligence that operate without human involvement. The imagined absence of people in thinking about Al limits our capacities to think of how such systems operate, shape and transform human lives, human labour, and organisational structures. We use prison labor as a starting point for exploring the collaborations and frictions around Al by re-establishing the human as a critical component in human-machine relationships. We base our discussion on interviews with prison administration, the Al firm and prison workers, as well as on observations of labeling work by prisoners. The closed prison is characterised by high safety requirements, vulnerable position of the prisoner-workers, unequal power relations and extreme control. While the prison is a high-tech environment in terms of security and surveillance, prisoners in closed wards have limited, controlled or no access to computers and information networks. The work of training Al introduces computers seen as highly charged and suspicious objects - in the prison environment, raising security concerns among prison guards. Prison labour is, therefore, an extreme example of ghost work, in which low-tech workers perform high-tech work in a digitally deprived environment. As such, we argue, it offers a fringe-case for thinking about questions related to human data labour that might not become visible in other contexts.

For the Al firm, prison labour is a strike of genius. While technologies for Al training are by now fairly easy to come by, in some cases finding human workforce to do the training is difficult. A Nordic welfare state is characterised by a limited supply of workers who have the necessary Finnish language skills and yet are willing to perform low-paid on- 
demand data generation tasks under precarious employment conditions. Prisons appear as an ideal frontier of expanding ghost work: cheap and untouched by competitors. Using prison labour to train Al appears as yet another form of capitalism's exploitation of the underprivileged. The Finnish prison system, however, does not treat prison labour as punitive. Instead, careful consideration is given to its rehabilitative aspects. In concrete terms this means that the prison administration views some of the most marginal prisoners in closed wards - women in male prisons, sex offenders, and youngsters - as ideal candidates for training the Al. Labeling data is seen as a promising area of rehabilitative work for these groups also because at least in theory the work is easily organised, safe, and doable in closed wards and solitary cells. Unlike typical Finnish prison labour, such as packaging, sewing, woodwork and folding laundry, training Al appears forward-looking and future-oriented. In terms of rehabilitation, computer-based work is hoped to support prisoners in their eventual return to civilian life. For prisoner-workers, training $\mathrm{Al}$ is one among freely chosen tasks and provides a very modest income (4,26 euros per day), slightly better than what, for instance, the packaging work provides. While those at the outside likely consider data labeling as simple and menial, reading and annotating can nevertheless be more interesting, cognitively challenging and rewarding than the alternatives.

Our empirical case offers a multisited view to the current ghost work landscape, reminds of its local and situational variations, underlining the importance of exploring its organizational arrangements. The case pushes us to see beyond the Al, to question how humans are participants in maintaining automated services, as objects of data collection and processing, in making sense of data and making decisions about data, and in implementing decisions. The case highlights how the organisational arrangements of Al training both work with and interfere in political-economic incentives and pressures, such as platformization (Srnicek, 2017) and the cascading logic of automating data production, processing and use (Andrejevic, 2016), which often seem omnipresent and incontestable. Here we follow seminal research that highlights not only human involvement in technological processes, but how humans are involved and thereby implicated in such processes (Suchman 1987). Ultimately, the organisational environment and everyday arrangements around Al-related tasks determine whether they are just and ethically robust. While prison labour might seem like straightforward exploitation - which it also often is - our case highlights other aspects such as new forms of rehabilitation and new opportunities for closed ward prisoners. The case also points towards a curious form of techno-optimism, rarely found in a closed prison, where technology is more conventionally an apparatus of control rather than opportunity.

\section{References}

Andrejevic, M. (2016). Theorizing Drones and Droning Theory. In A. Zavrsnik (Ed.), Drones and Unmanned Aerial Systems. Legal and Social Implications for Security and Surveillance, 21-44. Cham: Springer. https://doi.org/10.1007/978-3319-23760-2

Gray, M. L., \& Suri, S. (2019). Ghost Work. How to Stop Silicon Valley from Building a New Global Underclass. Boston, MA: Houghton Mifflin Harcourt.

Pendergrast, K. (2019). The next big cheap. Real Life, November 25.

https://reallifemag.com/the-next-big-cheap/

Suchman, L. A. (1987). Plans and Situated Actions: The Problem of Human-Machine 
Communication. Cambridge, UK: Cambridge University Press. Srnicek, N. (2017). Platform Capitalism. Cambridge, UK: Polity Press. 